DOI https://doi.org/10.30525/2592-8813-2021-1-1

\author{
Grigori Fainstein
}

\title{
DEVELOPMENT OF ESTONIAN TRADE PATTERNS
}

\begin{abstract}
This paper describes specialisation dynamics in Estonian export using revealed comparative advantage (RCA) and intra-industry trade (IIT) measures. We analyse the development of the distribution of comparative advantage using descriptive statistics and Galtonian regression. Intra-industry trade dynamic is analyzed using a marginal approach. We generally observe a stable specialization structure of Estonian exports in 2006-2011, along with some changes in specialization in the years following that. Based on the analysis of the RSA index and the Galtonian regression, we can make the conclusion about the diversification of the specialisation structure. The most important component of trade expansion in Estonia within the considered time period is the intra-industry trade. In 2016-2020 there was a significant increase in the specialization shift component in trade dynamic, which indicates the structural changes in Estonian exports. The most essential structural changes during the last five years occurred in such commodity sectors as food and live animals, animal and vegetable oils, as well as machinery and transport equipment, which were caused by the increasing share of specialization shift.

Key words: comparative advantage, specialization, trade patterns, intra-industry trade, Balassa index of revealed comparative advantage, Grubel-Lloyd index.
\end{abstract}

\section{Introduction}

From the time of obtaining independence essential structural changes occur in the Estonian economy. The same happens to the Estonian foreign trade flows. In the 1990s, the main factors of these developments included rapid reorientation from the markets of the former Soviet republics to the EU markets and the inflow of FDI; further changes were mainly determined by the economic crisis in Russia and the global financial crisis, as well as a number of shocks to the world economy in recent years, including the Covid-19 epidemic. The reorientation to European markets was initially facilitated by low production costs. With the integration into the European Union, the costs of production grew (primarily wages); this, in order to stay competitive, required Grigori Fainstein, Dr.oec., docent (Baltic International Academy, Riga, Latvia) an increase in the technical level and the product quality. This became possible due to the attraction of direct investments, primarily from the countries of the European Union.

Trade patterns development is a dynamic process, accompanied by a reallocation of resources between economic sectors, creates essential adjustment cost. Measurement of this cost, together with trade patterns dynamic, is the fundamental problems of economic analysis. The dynamic character of this process requires a special methodological approach. Thus, the aim of this paper is to apply this approach to Estonian trade patterns in order to analyse dynamic of specialization and intra-industry component of foreign trade in recent years.

For empirical analysis of Estonian trade patterns, we used export and import data time series from the UNSTAD database for 2006-2020. This data is available in the format of the Standard International Trade Classification (SITC) Revision 3 structure, and includes 255 commodity sectors in 3-digit level of aggregation, which will be aggregated in the process of analysis in 2-digit level commodity sectors.

The rest of the paper is structured as follows. In the second section we present the theoretical framework and discuss measuring problems, in the third section empirical analysis and results are presented, and following that comes the conclusion.

(C) Grigori Fainstein 


\section{Theoretical Framework and Measurement Problems of the Dynamics of Trade Patterns}

According to the traditional trade theory known as the Ricardian model of comparative advantage and its modern interpretation in the Heckscher-Ohlin model, the country's foreign trade patterns are determined by its relative factor endowments. This theory predicts changes in country's trade patterns only if its relative factor endowments change compared with those of its trading partners. Redding (2002) analysed changes in factor endowments in 7 OESD countries and concluded that these are important determinants of specialization development in the long run.

The most common measure of the structure of export flows on the basis of comparative advantage is the Balassa index of revealed comparative advantage (RCA), proposed by Balassa (1965). It is calculated as follows

where

$$
\mathrm{RCA}_{i}=\frac{X_{\mathrm{ij}} / \sum X_{\mathrm{ij}}}{X_{i}^{W} / \sum M_{i}^{W}}
$$

$X_{\mathrm{ij}}$ is an exports of commodity $\mathrm{i}$ in country $\mathrm{j}$

$X_{i}^{W}$ is a world export of commodity $i$.

Despite its popularity, the Balassa index has a number of problems when used in econometric analysis, where the main problem is its asymmetry. The index can take values from zero to infinity. From zero to one there is the comparative disadvantage zone and, accordingly, the comparative advantage zone is above one. As a result, the distribution of the index is skewed towards the right and the average is systematically higher than the median. To solve these problems, Dalum et al. (1998) developed a revealed symmetric comparative advantage index (RSCA), which is calculated according to the following formula.

$$
R S C A_{i}=\frac{R C A_{i}-1}{R C A_{i}+1}
$$

This index ranges from -1 to 1 and eliminates the biased distribution as well as the overestimation of sectors with a comparative advantage.

The new trade theory analyses the scale effect and intra-industry component of trade flows. It predicts that nature of scale economy affects specialization. In the case of internal economies of scale, the main implications of the factor proportions theorem do not change (Krugman 1987). In the presence of national external economies of scale, as shown by Wong (1995), trade patterns are determined by initial comparative advantage. According to Either (1982), external economy of scale reinforces specialisation.

Intra-industry trade as a result of scale effect constitutes a significant part of modern trade flows.

The most popular measure of the level of intra-industry trade is Grubel-Lloyd (GL) index (Grubel and Lloid, 1975):

$$
\mathrm{GL}_{i}=1-\frac{\left|X_{i}-M_{i}\right|}{\left(X_{i}+M_{i}\right)}
$$

where $\mathrm{Mi}$ - countries' imports of commodity group $\mathrm{i}$,

$\mathrm{X}_{\mathrm{i}}$ - countries' exports of commodity group $\mathrm{i}$.

This index ranges from zero to one and allows to analyse the level of intra-industry trade for commodity sectors, to aggregate them, and to make cross-country comparisons.

GL index is calculated over some particular period of time. To analyse trade dynamics, we have to compare different time periods. This comparative static approach, however, gives us little information about the dynamical changes in trade patterns. To overcome this problem, Brulhard (1994) proposed a measure of marginal intra-industry trade (MIIT):

$$
\operatorname{MIIT}_{i}=1-\frac{\left|\Delta_{t} X_{i}-\Delta_{t} M_{i}\right|}{\left|\Delta_{t} X_{i}\right|+\left|\Delta_{t} M_{i}\right|}
$$


where $\Delta_{t} X_{i}=X_{\mathrm{ti}}-X_{t-1, i}$

$$
\Delta_{t} M_{i}=M_{\mathrm{ti}}-M_{t-1, i}
$$

MIIT index can be aggregated across industries as a weighted average:

$$
\begin{array}{r}
\operatorname{MIIT}_{\text {total }}=\sum_{i=1}^{n} \operatorname{MIIT}_{i} * W_{i} \\
\text { Where } W_{i}=\frac{\left|\Delta_{t} X_{i}\right|+\left|\Delta_{t} M_{i}\right|}{\sum_{i=1}^{n}\left(\left|\Delta_{t} X_{i}\right|+\left|\Delta_{t} M_{i}\right|\right)}
\end{array}
$$

The MIIT index, unlike the GL index, reveals the structure of change in trade flows. This index also ranges from 0 and 1 .

\section{Empirical results}

Based on UNSTADE database we calculated the RSA index for Estonian trade flows for 20062020. We based our analysis of the data on the five-year averages in order to eliminate short-time fluctuations. The results of this calculation are submitted in Annex 1. The first conclusion is that in the aggregated level of commodity sectors the structure of comparative advantage in the considered time period did not undergo significant change.

Table 1. Descriptive statistics of RCA index distribution

\begin{tabular}{|c|c|c|c|}
\hline & $\mathbf{2 0 0 6 - 2 0 1 0}$ & $\mathbf{2 0 1 1 - 2 0 1 5}$ & $\mathbf{2 0 1 6 - 2 0 2 0}$ \\
\hline Mean & 1.214113 & 1.115938 & 1.112879 \\
\hline Standard Error & 0.239822 & 0.197538 & 0.193402 \\
\hline Median & 1.07542 & 1.087851 & 1.111871 \\
\hline Standard Deviation & 0.758385 & 0.624669 & 0.61159 \\
\hline Sample Variance & 0.575148 & 0.390211 & 0.374042 \\
\hline Kurtosis & 0.068956 & -0.22556 & 2.296867 \\
\hline Skewness & 0.789984 & 0.582434 & 0.931061 \\
\hline Range & 2.35805 & 1.937624 & 2.274245 \\
\hline Minimum & 0.15827 & 0.21513 & 0.199175 \\
\hline Maximum & 2.51632 & 2.152754 & 2.47342 \\
\hline Sum & 12.14113 & 11.15938 & 11.12879 \\
\hline
\end{tabular}

Source: author's calculations

Table 1 displays the basic parameters of the descriptive statistics for RCA index.

As can be seen, the mean value is above 1, indicating that essential part of comparative advantage is concentrated in sectors with a high value of the RCA index. We can also notice predominancy of the average over the median in all time intervals, indicating that the distribution of comparative advantage is biased towards the right. As a result of this distribution, the sectors characterized by high values of the RCA index will be over-weighted. Thus, the evolution of the country's comparative advantage mainly depends on the evolution of its competitive sectors (Dalum et al. 2001). Over time, the value of the average decreases as the value of the median increases, indicating a more equal distribution of comparative advantage by sectors.

The steady decrease in the standard deviation and the mean suggests a decline in the level of specialization. The diversification of specialization over time is also confirmed by the increase in the median value. 
The popular methodology for the analysis of the dynamic of comparative advantage is the Galtonian regression model. Thus, this approach was used in the analysis of specialization distribution by Dalum et al, (Dalum et al. 2001) and Ferto (Ferto 2007). As has been mentioned above, the RSA index is skewed towards the right, which makes it problematic to use it in the econometric analysis. To avoid these problems, in this analysis we used the RSCA index. The Galtonian approach estimates the linear model where the independent variable is the time-lagged value of a dependent variable. This allows us to estimate the level of mobility or convergence of the specialization structure over time:

$$
\operatorname{RSCAt} 2 \alpha j+\beta j R S C A j t 1+\varepsilon j
$$

where:

$\mathrm{t} 1$ and $\mathrm{t} 2$ are the first and last years of the analysis respectively

$\alpha$ and $\beta$ are the linear regression coefficients

$\varepsilon$ is the residual term

$\mathrm{j}$ is the number of sectors

The value of $\beta$ indicates the dynamics of comparative advantage:

The value of $\beta$ above one indicates an increase in specialization, which means that the country is specializing deeper in sectors in which it was initially specialized and decreasing its specialization in sectors with a low initial specialization. If $\beta$ is in the range from zero to one, its specialization pattern has weakened. A special case is when $\beta$ is less than zero, which points to a change in the sign of the RCSA index.

In Table 2, we presented the result of the Galtonian regression model based on Estonian RSCA index for the considered years.

Table 2. Galtonian regression of the RSCA index for 2006-2020 years

$\begin{array}{ll}\alpha & 0.02 \\ \beta & 0.62 \\ \text { t-value } & 4.1^{* * *} \\ \text { Adj. } \mathrm{R}^{2} & 0.66 \\ \text { F-statistics } & 16.6^{* * *}\end{array}$

Source: author's calculations

The result is statistically significant and supports the previous conclusion concerning the diversification of the specialization structure.

The next step of the analysis is to calculate the dynamic index of the intra-industry trade MIIT. The results of that calculation are presented in the Annex 2. Using this index, we can analyse the dynamic of all components of trade flows. For this purpose, we used the methodology described in Bastos et al. (Bastos et al. 2007). Following this approach, we decomposed the marginal inter-industry trade (which is the different between one and MIIT) between two components: increasing of previous specialisation (IPS) and specialisation shift (SS):

$$
\text { INTER }=\left\{\begin{array}{c}
I P S \text { ifsing }\left(\Delta_{t} X_{i}-\Delta_{t} M_{i}\right)=\operatorname{sign}\left(X_{i 0}-M_{i 0}\right) \\
S S \text { ifsing }\left(\Delta_{t} X_{i}-\Delta_{t} M_{i}\right) \neq \operatorname{sign}\left(X_{i 0}-M_{i 0}\right)
\end{array}\right.
$$

Where $X_{i 0}$ export of sector $i$ at the beginning of period $t$

$M_{i 0}$ import of sector $i$ at the beginning of period $t$ 
As in the case of MIIT, we can aggregate these measures across economic sector to the country level as a weighted average:

$$
\begin{aligned}
& \mathrm{IPS}_{\text {total }}=\sum_{i=1}^{n} \mathrm{IPS}_{i} * W_{i} \\
& \mathrm{SS}_{\text {total }}=\sum_{i=1}^{n} \mathrm{SS}_{i} * W_{i}
\end{aligned}
$$

In Table 3, the aggregated components of trade flows dynamic are presented. As with the RCA index, we analysed 5-year average indicators to eliminate short run fluctuations. For comparison, we also included data for 1996 - 2005 from our previous culculations (Fainstein 2015).

Table 3. Aggregated components of trade dynamic

\begin{tabular}{|c|c|c|c|c|c|}
\hline Component & $\mathbf{1 9 9 6 - 2 0 0 0}$ & $\mathbf{2 0 0 1 - 2 0 0 5}$ & $\mathbf{2 0 0 6 - 2 0 1 0}$ & $\mathbf{2 0 1 1 - 2 0 1 5}$ & $\mathbf{2 0 1 6 - 2 0 2 0}$ \\
\hline IPS & 0,33 & 0,35 & 0.25 & 0.25 & 0.22 \\
\hline SS & 0,23 & 0,24 & 0.2 & 0.13 & 0.32 \\
\hline MIIT & 0,44 & 0,40 & 0.55 & 0.62 & 0.46 \\
\hline
\end{tabular}

Source: author's calculations

We can see that the most important component in trade development is the share of intra-industry trade, both in the considered period and in the long term. The general tendency shows an increase of this share with the exception of the last five years. Specialisation shift shows the stable dynamic until 2010. In 2011-2015, IPS plays the dominant role in trade expansion of inter-industry component of trade flows; having said that, specialisation shift becomes dominant in the next five years. The main reasons for that are likely to be export demand shocks associated with the macroeconomic dynamics in the Euro Zone as well as the economic consequences of the Covid-19.

In Table 4, the calculated indicators are presented at the level of aggregated SITS commodity sectors.

Table 4. Components of trade dynamic by aggregated commodity sectors in Estonia

\begin{tabular}{|c|c|c|c|c|c|c|c|c|c|}
\hline \multirow{2}{*}{ Sector } & \multicolumn{3}{|c|}{$\mathbf{2 0 0 6 - 2 0 1 0}$} & \multicolumn{3}{c|}{$\mathbf{2 0 1 1 - 2 0 1 5}$} & \multicolumn{3}{c|}{$\mathbf{2 0 1 6 - 2 0 2 0}$} \\
\cline { 2 - 11 } & IPS & SS & MIIT & IPS & SS & MIIT & IPS & SS & MIIT \\
\hline Food and live animals & 0.04 & 0.14 & 0.81 & 0.18 & 0.07 & 0.75 & 0.20 & 0.51 & 0.29 \\
\hline Beverages and tobacco & 0.17 & 0.06 & 0.77 & 0.30 & 0.01 & 0.69 & 0.27 & 0.28 & 0.45 \\
\hline Crude materials, inedible, except fuels & 0.12 & 0.39 & 0.48 & 0.41 & 0.00 & 0.59 & 0.36 & 0.25 & 0.39 \\
\hline $\begin{array}{c}\text { Mineral fuels, lubricants } \\
\text { and related materials }\end{array}$ & 0.32 & 0.20 & 0.48 & 0.04 & 0.21 & 0.76 & 0.09 & 0.11 & 0.80 \\
\hline $\begin{array}{c}\text { Animal and vegetable oils, } \\
\text { fats and waxes }\end{array}$ & 0.14 & 0.23 & 0.63 & 0.26 & 0.27 & 0.46 & 0.35 & 0.56 & 0.09 \\
\hline Chemicals and related products, n.e.s. & 0.21 & 0.07 & 0.72 & 0.42 & 0.11 & 0.47 & 0.32 & 0.04 & 0.65 \\
\hline Manufactured goods & 0.33 & 0.04 & 0.62 & 0.37 & 0.18 & 0.45 & 0.23 & 0.10 & 0.66 \\
\hline Machinery and transport equipment & 0.31 & 0.27 & 0.42 & 0.18 & 0.14 & 0.68 & 0.21 & 0.60 & 0.19 \\
\hline Miscellaneous manufactured articles & 0.19 & 0.23 & 0.59 & 0.39 & 0.07 & 0.53 & 0.21 & 0.19 & 0.59 \\
\hline
\end{tabular}

Source: author's calculations

For food and live animals, which are essential sectors of the Estonian export, we can observe the domination of intra-industry component in trade dynamic until 2016, and essential specialization shift in the last five years. The intra-industry component remains dominant in trade expansion in such leading Estonian export sections as manufactured goods and miscellaneous manufactured articles. 
Overall, we can observe essential changes in trade dynamic in the last 5-year period. The dominant tendency has to do with the increasing role of specialization shift in trade expansion among the most important commodity groups (which are in possession of comparative advantage). In the analysis of the initial data of exports and imports we usually observe an absolute decrease in this period due to the macroeconomic shocks.

\section{Conclusions}

Based on the RCA index, we generally observe a stable specialization structure of Estonian exports in 2006-2011, along with some changes in specialization in the years following that. The level of specialization by commodity groups mostly decreases over time.

Based on the analysis of the RSA index and the Galtonian regression, we can make the conclusion about the diversification of the specialisation structure over time.

The most important component of trade expansion in Estonia within the considered time period is the intra-industry trade. In 2016-2020 there was a significant increase in the specialisation shift component in trade dynamic, which indicates the structural changes in Estonian exports.

The most essential structural changes during the last five years occurred in such commodity sectors as food and live animals, animal and vegetable oils, as well as machinery and transport equipment, which were caused by the increasing share of specialization shift.

\section{Annex 1}

RCA index for Estonian trade flows (5-year average)

\begin{tabular}{|c|c|c|c|}
\hline Sector & $\mathbf{2 0 0 6 - 2 0 1 0}$ & $\mathbf{2 0 1 1 - 2 0 1 5}$ & $\mathbf{2 0 1 6 - 2 0 2 0}$ \\
\hline Food and live animals & 2.447 & 2.153 & 1.325 \\
\hline Beverages and tobacco & 2.516 & 2.092 & 2.473 \\
\hline Crude materials, inedible, except fuels & 0.987 & 0.812 & 1.308 \\
\hline Mineral fuels, lubricants and related materials & 0.832 & 0.619 & 0.710 \\
\hline Animal and vegetable oils, fats and waxes & 0.542 & 0.589 & 0.559 \\
\hline Chemicals and related products, n.e.s. & 1.266 & 1.164 & 1.239 \\
\hline Manufactured goods & 0.821 & 1.012 & 0.859 \\
\hline Machinery and transport equipment & 1.408 & 1.302 & 1.332 \\
\hline Miscellaneous manufactured articles & 0.158 & 0.215 & 0.199 \\
\hline
\end{tabular}

Source: author's calculations

Annex 2

MIIT index for Estonian trade flows (5-year average)

\begin{tabular}{|c|c|c|c|}
\hline Sector & $\mathbf{2 0 0 6 - 2 0 1 0}$ & $\mathbf{2 0 1 1 - 2 0 1 5}$ & $\mathbf{2 0 1 6 - 2 0 2 0}$ \\
\hline Commodities total & 0.54 & 0.62 & 0.46 \\
\hline Food and live animals & 0.81 & 0.75 & 0.29 \\
\hline Beverages and tobacco & 0.77 & 0.69 & 0.45 \\
\hline Crude materials, inedible, except fuels & 0.48 & 0.59 & 0.39 \\
\hline Mineral fuels, lubricants and related materials & 0.48 & 0.76 & 0.80 \\
\hline Animal and vegetable oils, fats and waxes & 0.63 & 0.46 & 0.09 \\
\hline Chemicals and related products, n.e.s. & 0.72 & 0.47 & 0.65 \\
\hline Manufactured goods & 0.62 & 0.45 & 0.66 \\
\hline Machinery and transport equipment & 0.42 & 0.68 & 0.19 \\
\hline Miscellaneous manufactured articles & 0.59 & 0.53 & 0.59 \\
\hline
\end{tabular}

Source: author's calculations 


\section{References}

Balassa B. (1965) Trade Liberalization and Revealed Comparative Advantage. - The Manchester School of Economic and Social Studies. No 33. P. 99-123.

Bastos P., Cabral M. (2007) The Dynamics of International Trade Patterns. - Review of World Economics (Weltwirtschaftliches Archiv). Springer. Vol. 143 (3). October. P. 391- 415.

Brülhard M. (1994) Marginal Intra-Industry Trade: Measurement and Relevance for the Pattern of Industrial Adjustment. - Weltwirtschaftliches Archiv. Vol. 130. P. 600 - 613.

Dalum B, Laursen K, Villumsen G. (1998) Structural Change in OECD Export Specialisation Patterns: De-Specialisation and 'Stickiness'. - International Review of Applied Economics. No 12 (2) P. 423 - 443.

Either W. J. (1982) National and International Return to Scale in the Modern Theory of International World Trade. - American Economic Review. No 72. P. 389 - 405.

Grubel H.G., Lloyd P.J. (1975) Intra-Industry Trade. The Theory and Measurement of International Trade in Different Products. London.

Fainštein G., Matina E. (2015). Trade dynamics and adjustment costs in the Baltic States. - Economic Sciences. No 4 (125). P. $164-169$.

Ferto I. (2007) The Dynamics of Trade in Central and Eastern European Countries. - Managing Global Transitions, University of Primorska, Faculty of Management Koper. No 5 (1). P. 5 -23.

Krugman P. (1987) The Narrow Moving Band, the Dutch Disease, and the Competitive Consequences of Mrs. Thatcher: Notes on Trade in the Presence of Dynamic Scale Economies. - Journal of Development Economics. No 27 (1). P. 4 - 54.

Redding S. (2002) Specialization Dynamics. - Journal of International Economics. No 58 (1). P. 299 - 334.

Wong K. (1995) International Trade in Goods and Factor Mobility. MIT Press, Cambridge. 